\title{
High Speed Electrical Drives - Perspective of VFD Manufacturer
}

\author{
Martin Bruha ${ }^{1, *}$, Kai Pietiläinen ${ }^{1}$, and Axel Rauber ${ }^{1}$ \\ ${ }^{1}$ ABB Switzerland Ltd, Medium Voltage Drives, 5300 Turgi, Switzerland
}

\begin{abstract}
This paper deals with high-speed electrical drives utilizing power electronic converters (commonly abbreviated as ASD, VFD or VSD). Existing solutions vary mainly on the motor side while the power electronic converter is very similar for all cases. Various advantages as well as technical challenges are discussed and illustrated. At certain stages comparisons between conventional and high-speed drives are made. The paper summarizes the experience of a VFD manufacturer based on state of the art technology in medium voltage and multi-megawatt power range. The authors believe that main complexity around highspeed drives is the motor design while the VFD requires only small adaptations or can sometimes be used directly without any modifications of standard design. The technology readiness is evaluated to be on a medium to high level.
\end{abstract}

\section{Introduction}

Variable frequency drives (VFD) gain increasing popularity across many industries. The various applications have very different speed ranges from ultralow speed machines such as large mills in mining and minerals industry, low speed rolling mills in metals industry, medium speed pumps and fans up to high speed turbomachinery in oil and gas sector. The motor is connected with the load machine either directly or through a gear.

In turbomachinery a competing technology to VFD is a gas turbine or steam turbine. The turbine rotates with high speed and is directly coupled to the load machine (typically compressor) without any gear. Due to environmental aspects, easier controllability, reduced maintenance and other motivations there is a trend to replace such turbines with all electric drive system. In some cases both conventional and high-speed technologies can be used. However, if there are space and weight restrictions high-speed technology might be the only solution. Another case is e.g. electric motor drive as starter/helper with gas turbine as main driver. VFD technology also allows the use of 4-pole machines for higher speeds by increasing stator frequency.

As the authors illustrate, the VFD design for a highspeed application does not significantly differ from a conventional VFD. It is either a standardized product with small adaptations or even completely free of any modifications. The electric motor, on the other hand, is the component with higher complexity. One step from a conventional motor is motor with increased speed and 'standard' bearings. If the speed range requires magnetic bearings the complexity goes again one step higher.

\section{Variable speed solutions for turbomachinery}

\subsection{Motor technology}

First, it shall be defined what is a high-speed application, resp. where the high-speed range starts. To authors' knowledge there is no standardized classification in this regard. One can distinguish between conventional speed, semi high-speed and high-speed motors. In this paper conventional speed is considered up to $3^{\prime} 600 \mathrm{rpm}(60 \mathrm{~Hz}$ / 2-pole machine). Semi high-speed is up to approx. 6'400 - 7'500 rpm [1]. Above 7'500 rpm it is usually specific high-speed design with active magnetic bearings [2-5]. These considerations apply to larger machines in power range of several megawatt. Obviously, for smaller machines it is easier to achieve higher speed.

For turbomachinery applications there are principally two solutions: conventional technology with a gearbox or high-speed direct drive, also called gearless.

Conventional solution in electrically driven turbomachinery is a standard 4-pole electric motor with rated speed 1'500 rpm or 1'800 rpm (or somewhere nearby those speeds) and speed-increasing gear. Due to the gear the motor and compressor speeds are decoupled. Such motor design is derived from a direct on-line (DOL) design while considering variable speed operation and inverter duty.

Direct drive solution utilizes motor with same speed as the driven machine. It eliminates the gear and its mechanical losses. The installation is typically more compact than the conventional approach. That fact makes it attractive in case of space or weight restrictions. The complexity is around the active magnetic bearings and their control. 


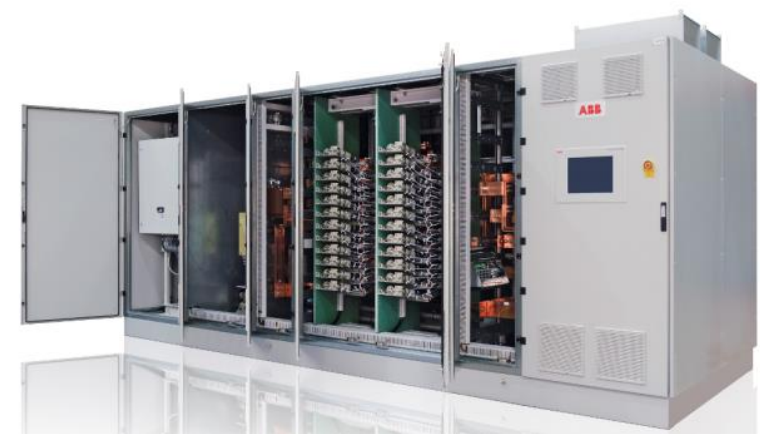

Fig. 1. Typical LCI converter suitable to supply conventional as well as (semi) high-speed motors.

If the speed of turbomachine is not too high (semi high-speed) then a 2-pole turbo-motor can be used. Such motor is usually a round rotor type of synchronous machine derived from a turbo-generator and eventually adopted for higher speed. Maximum speed can reach approx. 7'500 rpm. Such design is normally supercritical meaning that motor is operated above the first critical speed. This brings some challenges in case the controllable speed range is very wide. In lower semi high-speed range (up to approx. 4'000 rpm, eventually higher) 4-pole rotor design with higher supply frequency can be realized. The 4-pole rotor has fundamentally different mechanical behaviour compared to his 2-pole counterpart. Its design is sub-critical providing many benefits with respect to critical speeds. This approach with 4-pole rotor is followed by many leading manufacturers and some machines have already been manufactured $[6,7]$.

For speeds above $7^{\prime} 000-8^{\prime} 000 \mathrm{rpm}$ the solution is usually induction motor with magnetic bearings. Several rotor designs can be used with their pros and cons. Main solutions are variants of solid cylindrical rotor and laminated rotor with special shaft arrangement [8].

\subsection{VFD technology}

Variable frequency drive (VFD) for high-speed application nowadays does not significantly differ from a conventional VFD. Drive configuration suggested in [2] with so called twin inverter configuration and open winding stator design is principally still possible, but there are meanwhile more straight forward ways. The power hardware is either the same as conventional VFD or it experiences minor modifications. The inverter modulation scheme might be different. As for conventional drives also for high-speed two basic technologies are available: current source inverters (CSI) and voltage source inverters (VSI).

\subsubsection{Load-commutated inverter (LCI)}

LCI is a specific category of current source inverters. Both line side and motor side converters consist of classical thyristors commutated by external voltage source: grid voltage on the line side and motor voltage on the motor side. This explains the name 'loadcommutated' and also the fact that LCI only works in combination with synchronous machine. LCI is very mature and reliable technology that is available on the market since 1970s. Due to easy power and voltage scalability a very high-power drive can be realized without too much complexity and with low parts count. Although majority of the LCI drive applications have rated output frequency in the range 40 to $60 \mathrm{~Hz}$ the drive can reach output frequency up to $100 \ldots 120 \mathrm{~Hz}$ with minimum modifications. In combination with 2-pole turbo-motor a direct drive with up to 7'200 rpm can be realized [1].

First projects semi high-speed LCI driven motors had already been realized in early 1980 s and some installations therefore reached over 30 years operational experience demonstrating high reliability and availability.

\subsubsection{Voltage source inverter (VSI)}

VSI technology became dominant in 1990s with the evolution of self-commutated power electronic switches (first GTO thyristors, later IGCT thyristors and IGBT

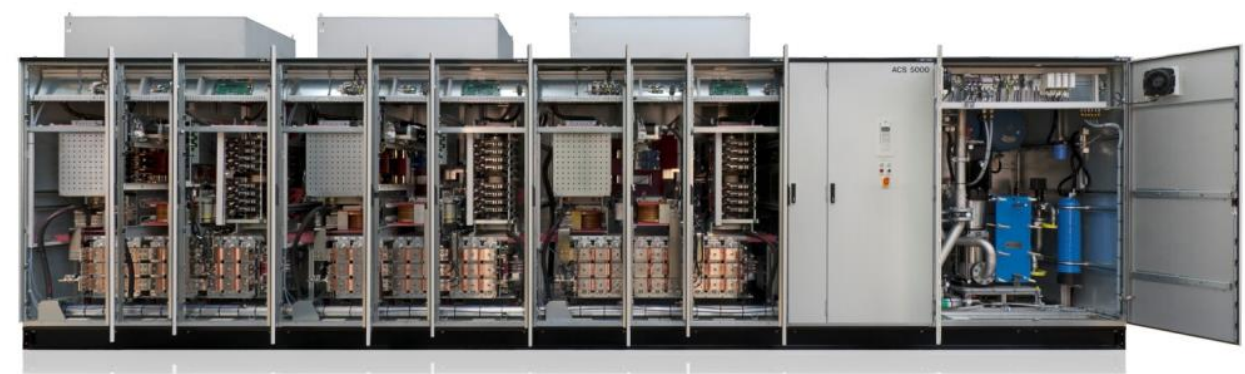

Fig. 2. Typical VSI converter (5-L NPC) suitable to supply conventional as well as high-speed motors. 
transistors). Nowadays VSI drives represent vast majority of all new electric drive installations. There are several topologies on the market. In medium voltage range the most common are 3-level neutral point clamped (3-L NPC) inverter, 5-level neutral point clamped (5-L NPC) inverter, multiwinding multicell or modular multilevel converter (MMC, M2C). Topology further described is a 5-L NPC inverter which in fact consists of 3-L-NPC modules in H-bridge connection. It is " $6 \mathrm{kV}$ class" VFD with rated output voltage selectable in the range $5.5 \mathrm{kV}$ to $7.2 \mathrm{kV}$. The liquid cooled variant offers power range starting from approx. $6 \mathrm{MW}$ up to almost $40 \mathrm{MW}$ as single unit. Higher power is achieved by paralleling multiple units. Standard output frequency is up to $66 \mathrm{~Hz}$ in conventional applications. In highspeed configuration more than $250 \mathrm{~Hz}$ output frequency can be easily reached (field reference up to $260 \mathrm{~Hz}$, technical feasibility up to at least $400 \mathrm{~Hz}$ ).

VSI type of converter can supply both induction and synchronous machine and the true high-speed applications typically consist of cage induction machine and active magnetic bearings (AMB).

\section{VFD design considerations for high- speed}

\subsection{Modulation technique and switching frequency}

\subsubsection{Load-commutated inverter (LCI)}

The inverter is load-commutated and the principle is the same as in conventional drive system. Higher output frequency might lead to small adaptations of the snubber circuit and more frequent commutation shall be considered in voltage design, but otherwise the LCI is basically the same regardless if designed for rated motor frequency of $50 \mathrm{~Hz}$ or $100 \mathrm{~Hz}$. Semi high-speed synchronous machines with 2-pole round rotor usually inherently have quite low sub-transient reactance which is beneficial for LCI operation. The commutation notches are smaller and the inverter can operate with better (higher) firing angle. This fact in turn means

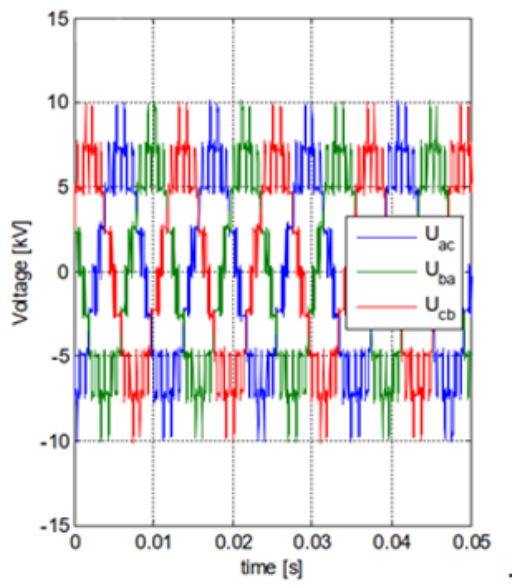

Fig. 4. VFD output voltage at $84.5 \mathrm{~Hz}$ (left) and $120.5 \mathrm{~Hz}$ (right). higher power factor and lower torque ripple.

\subsubsection{Voltage source inverter (VSI)}

High speed applications naturally need higher fundamental output frequency of the inverter. Too high switching frequency would cause high additional losses, higher semiconductor junction temperatures and consecutive power derating of VFD. Example of inverter loadability versus semiconductor switching frequency is shown in Fig. 3. The VFD has certain design margin so that small increase of switching frequency does not cause any power derating. However, above certain frequency the current derating becomes significant eventually leading to uneconomical VFD design.

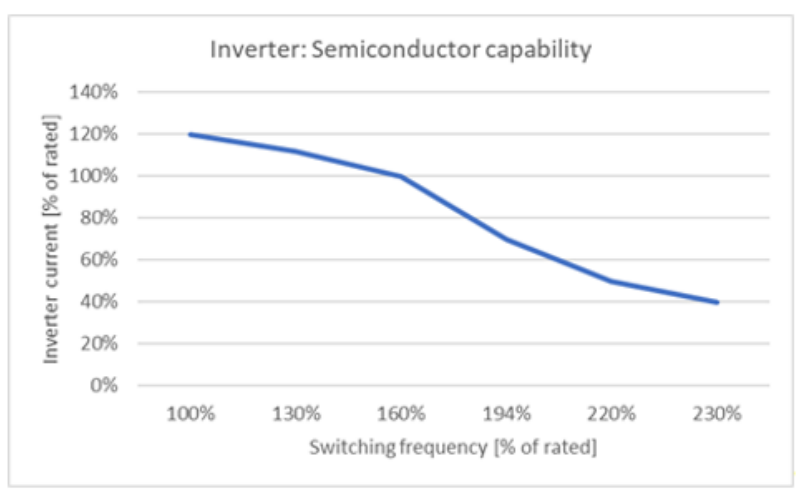

Fig. 3. Inverter capability versus semiconductor switching frequency.

Therefore, different modulation scheme is used than in conventional applications. Optimized pulse pattern (OPP) provides a good balance between good output waveform and reasonable switching frequency. It allows operation with lower ratio between switching frequency and fundamental output frequency. Several OPPs are pre-defined in the software and the VFD changes automatically from one PP to another one at certain motor fundamental speeds. Those speed thresholds are defined project specifically as part of system design. Such flexibility allows optimization between low current harmonics and maximum utilization of VFD.

The output voltage is axis-symmetrical with pulse pattern modulation. Plots in Fig. 4 show real field

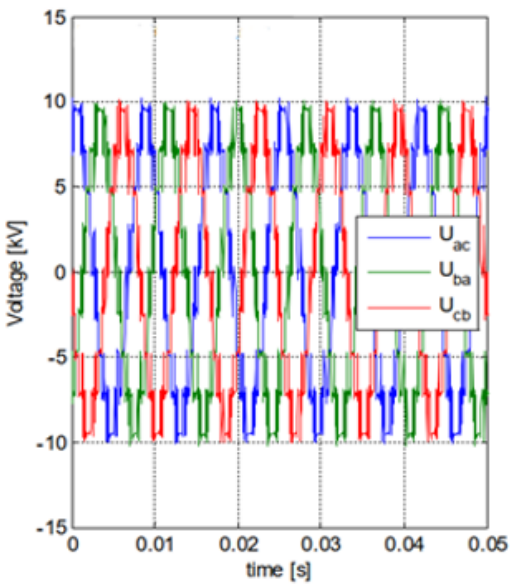


Table 1. Drive system efficiency: Conventional versus high-speed.

\begin{tabular}{|l|c|c|c|c|}
\hline Motor type & $\begin{array}{c}\text { Induction, } \\
\text { conventional }\end{array}$ & $\begin{array}{c}\text { Synchronous, } \\
\text { conventional }\end{array}$ & $\begin{array}{c}\text { Induction, } \\
\text { high-speed }\end{array}$ & $\begin{array}{c}\text { Induction, } \\
\text { high-speed }\end{array}$ \\
\hline Shaft power [kW] & $12^{\prime} 000$ & $12^{\prime} 000$ & $12^{\prime} 245$ & $12^{\prime} 245$ \\
\hline Motor voltage [kV] & 6.6 & 6.6 & 6.6 & 6.6 \\
\hline Motor current [A] & $1{ }^{\prime} 198$ & $1{ }^{\prime} 090$ & $1{ }^{\prime} 395$ & $1^{\prime} 392$ \\
\hline Rated speed [rpm] & $1{ }^{\prime} 493 / 1{ }^{\prime} 793$ & $1^{\prime} 500 / 1{ }^{\prime}, 800$ & $12^{\prime} 000$ & $12^{\prime} 000$ \\
\hline Power factor [pu] & 0.92 & 1.00 & 0.80 & 0.80 \\
\hline Gear efficiency [\%] & $98.00 \%$ & $98.00 \%$ & N/A & N/A \\
\hline Motor efficiency [\%] & $97.20 \%$ & $98.30 \%$ & $96.00 \%$ & $96.20 \%$ \\
\hline Switching frequency & Standard & Standard & Increased & Standard \\
\hline Output choke & No & No & No & Yes \\
\hline VFD heat loss [kW] & 133 & 121 & 172 & 200 \\
\hline VFD efficiency [\%] & $98.96 \%$ & $99.04 \%$ & $98.67 \%$ & $98.45 \%$ \\
\hline Combined efficiency VFD-Motor-Gear [\%] & $94.26 \%$ & $95.41 \%$ & $94.72 \%$ & $94 . \%$ \\
\hline
\end{tabular}

measurements for two different motor speeds (measured signals plotted in MATLAB $^{\circledR}$ environment).

\subsection{Efficiency and losses}

Efficiency is nowadays very important performance criteria as it directly impacts the operational expenditure (OPEX) and return of investment. Proper efficiency assessment shall always be done on system level. Benchmarking of individual system components might be misleading. For example, one VFD design has higher efficiency, but its output waveform contains lot of harmonics that cause additional losses in the motor. It shall be stated if the efficiency includes all auxiliary consumption or not.

VFD with higher output frequency tendentially has somewhat higher losses. As a rule of thumb approx. 1/3 of total losses is scaled up with increased switching frequency. The high-speed motor has somewhat lower efficiency than a conventional one. However, the elimination of gear saves 2 to $3 \%$ of throughput power. In Table 1 typical values are provided considering a drive system with $12 \mathrm{MW}$ compressor input power. The drive system consists of (a) conventional induction machine, (b) conventional synchronous machine, (c, d) high-speed induction machine and VFD without and with output reactor (choke).

Gear efficiency of $98 \%$ is assumed. Different gear value could potentially shift the results little bit. Input

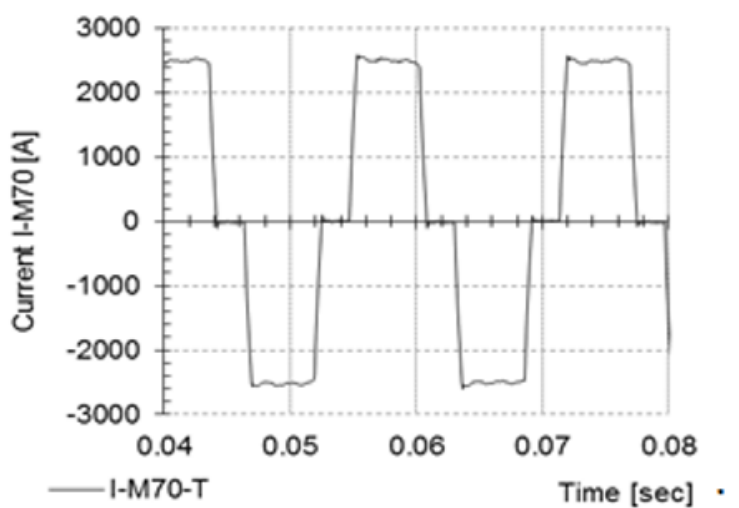

transformer is disregarded in comparison as it would have approx. the same efficiency for each case and is 'neutral' in that sense. VFD losses include auxiliary consumption, such as cooling water pumps, cooling fans, control boards etc. It is obvious that overall efficiency is very similar in all cases. High-speed electrical drives have somewhat higher losses (both VFD and motor) that are offset by the mechanical losses of the speed increasing gear.

\subsection{VFD motor friendliness}

Motor friendliness is important characteristic of VFD to ensure compatibility with the electric motor. In case the motor is located in hazardous area the compatibility is even more critical and shall be carefully checked.

\subsubsection{Load-commutated inverter (LCl)}

The advantage of LCI is that the motor voltage is almost sinusoidal with typical commutation notches (see Fig. 5 as example) and the motor insulation system requires only small margin compared to direct on-line motor. The output current and torque contain harmonics that need to be respected in motor design.

LCI configured as full drive, i.e. for continuous operation, typically consists of a 12-pulse inverter in combination with dual star stator winding on the

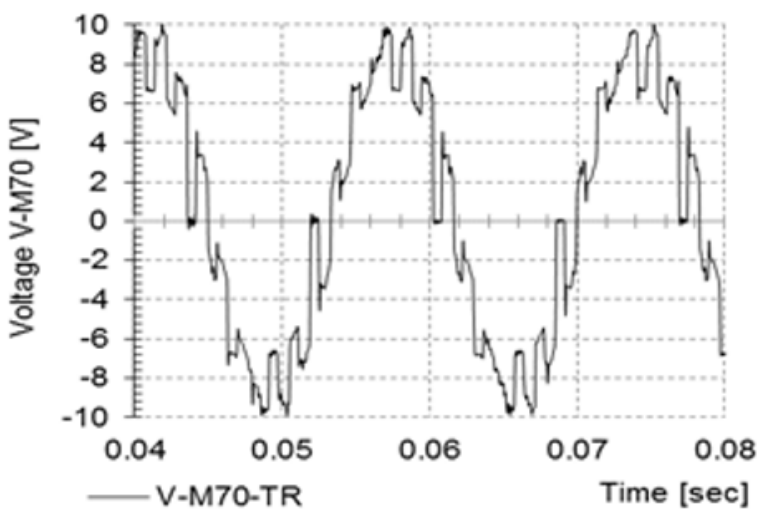

Fig. 5. Current and voltage output waveform of LCI (37'000 kW / 1'800 rpm). 


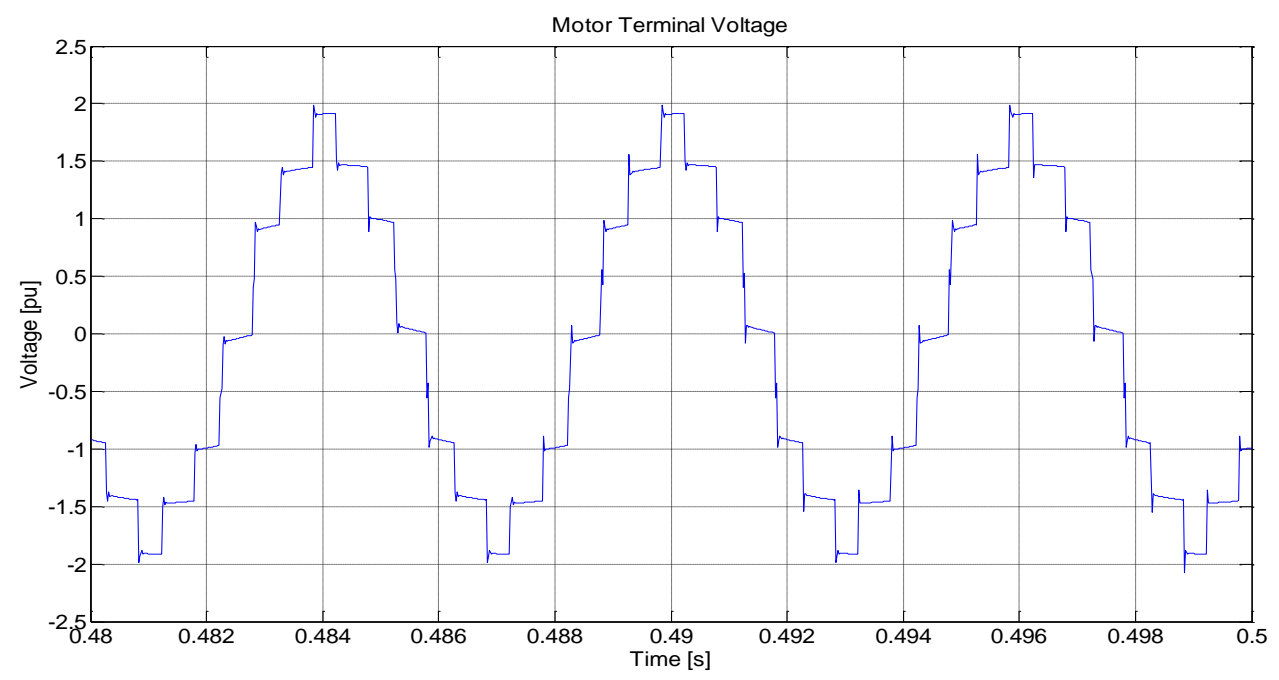

Fig. 6. Motor phase-phase voltage at $166.7 \mathrm{~Hz}$.

machine. The stator windings have relative displacement of $30^{\circ}$ electrical $\left(\mathrm{YY} 30^{\circ}\right)$. Such phase shifting helps to reduce the current and torque harmonics in the machine by up to 3-times compared to 6-pulse inverter and standard three phase motor.

\subsubsection{Voltage source inverter (VSI)}

If the VFD has a full-blown grounded sine filter at its output, there are no special considerations for the motor apart from mechanical design and cooling supporting variable speed operation [9]. However, sine filter is not common in high-speed and/or high-power range. The physical size of sine filter would be very large at high power. There are also extra losses associated with sine filter. And finally, there is the topic of self-excitation which might be even more challenging for wide speed control range.

For all other topologies (without sine filter at the output) the VFD has certain impact on motor. Generally, the more voltage steps (levels) in the output waveform the closer is the waveform to the ideal sine wave.

It can be divided into two categories: output voltage waveform influencing insulation system of motor and output current waveform impacting thermal design of motor.

For the integrity of motor insulation following VFD parameters are typically asked:

- Peak phase to phase voltage

- Peak phase to ground voltage

- Peak neutral to ground (common mode) voltage

- Voltage rate of rise $(\mathrm{dv} / \mathrm{dt})$

Example of output voltage waveform is displayed in Fig. 6. Note that scaling of y-axis is based on phase to ground nominal voltage.

For the thermal design of motor following information is typically asked either for worst case point or for certain design or envelope points:

- Frequency spectrum of motor current

- Total current harmonic distortion (THDi)

The motor friendliness can be enhanced by using an output choke. The choke is specifically designed for high frequency operation. It is either stand-alone unit or integrated inside VFD panel. The integrated version allows easier handling and installation. Choke is directly water-cooled (WF) sharing the same deionized water with the VFD. The majority of heat losses of the choke are dissipated into water avoiding extra heat load for airconditioning system of the electric room. Fig. 7 shows an example from the assembly.
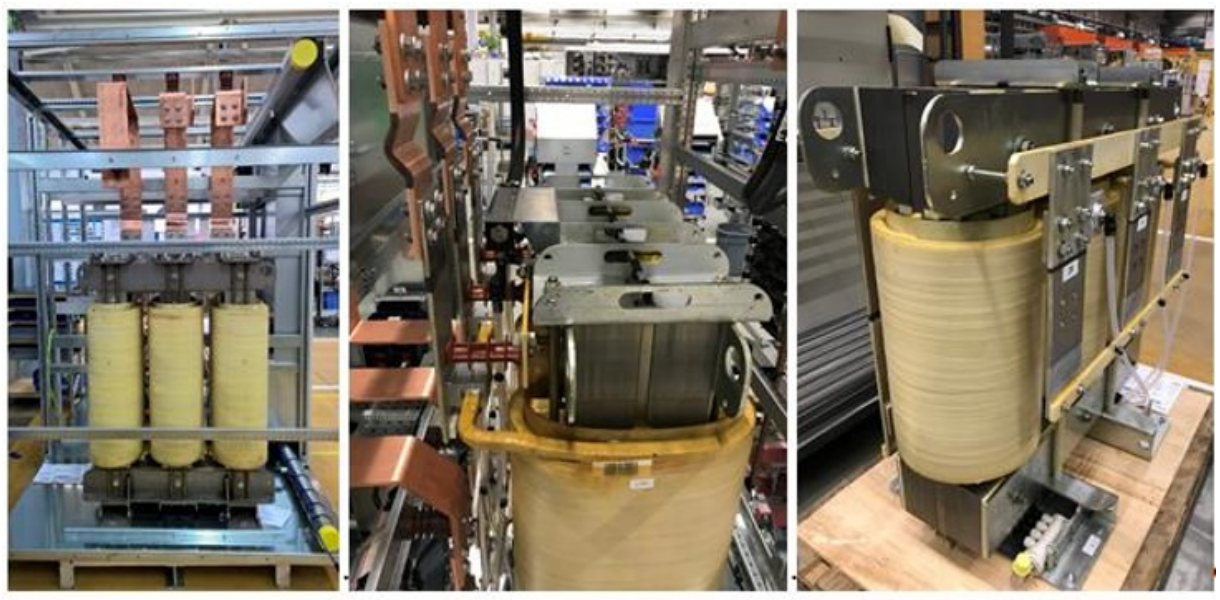

Fig. 7. Output choke integrated inside VFD lineup and directly water cooled. 

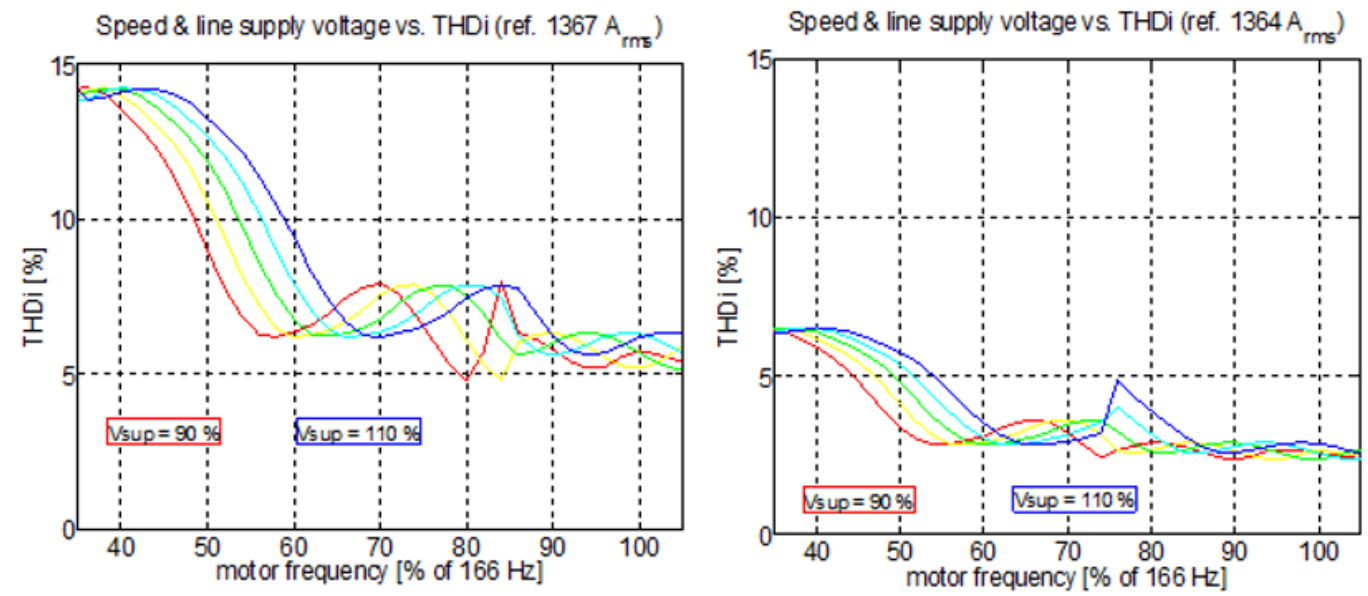

Fig. 8. Motor current distortion (THDi) across motor speed and line supply variation.

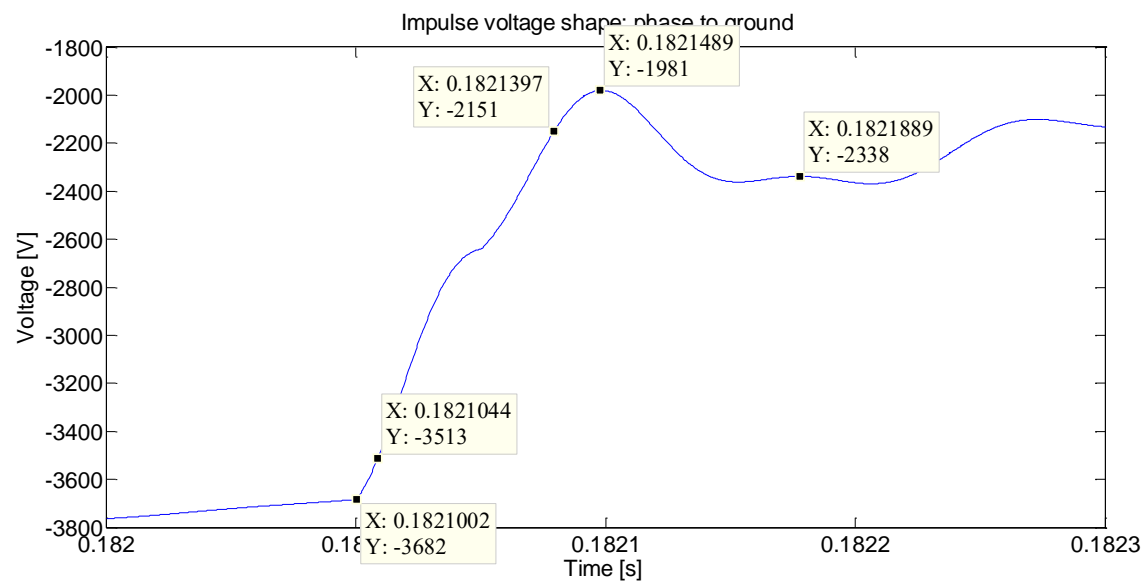

Fig. 9. Voltage impulse waveshape (phase-ground).

The positive impact of the output choke on the motor current distortion (THDi) is depicted in Fig. 8. The graphs show the dependence on the motor fundamental frequency and incoming supply voltage variation. The pulse patterns change at pre-programmed motor speed that can be project-specifically shifted. The supply voltage affects the dc voltage and therefore the modulation index at given speed and in turn also THDi.

Presence of output choke also reduces the rate of rise $(\mathrm{dv} / \mathrm{dt})$ of the inverter output voltage. Detail of voltage waveform is depicted in Fig. 9.

Parameters determined from the waveshape as per [10] are shown in Table 2:

Table 2. Parameters of voltage impulse waveshape.

\begin{tabular}{|l|c|c|}
\hline $\mathrm{t}_{10}$ & {$[\mathrm{~s}]$} & 0.1821044 \\
\hline $\mathrm{t}_{90}$ & {$[\mathrm{~s}]$} & 0.1821397 \\
\hline $\mathrm{t}_{\mathrm{r}}$ & {$[\mathrm{s}]$} & $3.53 \mathrm{e}-5$ \\
\hline $\mathrm{U}_{\mathrm{p}}$ & {$[\mathrm{V}]$} & 1701 \\
\hline $\mathrm{U}_{\mathrm{b}}$ & {$[\mathrm{V}]$} & 357 \\
\hline $\mathrm{U}_{\mathrm{a}}$ & {$[\mathrm{V}]$} & 1344 \\
\hline $\mathrm{dv} / \mathrm{dt}$ & {$[\mathrm{V} / \mu \mathrm{s}]$} & 38.5 \\
\hline
\end{tabular}

Remark: Simulation results do not consider effects of motor cables and non-linearity of components at high frequencies. Recommended $\mathrm{dv} / \mathrm{dt}$ for insulation consideration is increased to $120-150 \mathrm{~V} / \mu \mathrm{s}$. That is still much lower value compared to standard inverter with typical dv/dt of $1^{\prime} 000-3^{\prime} 000 \mathrm{~V} / \mu \mathrm{s}$.

\subsection{VFD load friendliness}

The VFD-motor drive system shall also be load friendly. VFD driven motor inherently has certain torque ripple that influences torsional behaviour of the entire shaft string [11]. It must be ensured that all shaft components are properly dimensioned for the alternating torque occurring in normal operation as well as transient torque during possible fault conditions. Therefore, torque ripple of the VFD driven motor shall be kept within certain limits. More important than the overall peak-peak torque is however the frequency spectrum of the motor torque $[12,13]$. The frequency content of the motor torque defines if torsional modes of the shaft string will be excited or not. This is of utmost importance in modern turbomachinery as the damping values are extremely small and the amplification factors correspondingly large. In other words, even a small excitation torque can cause large alternating torque on the shaft components (e.g. couplings) when the frequency of motor air gap 

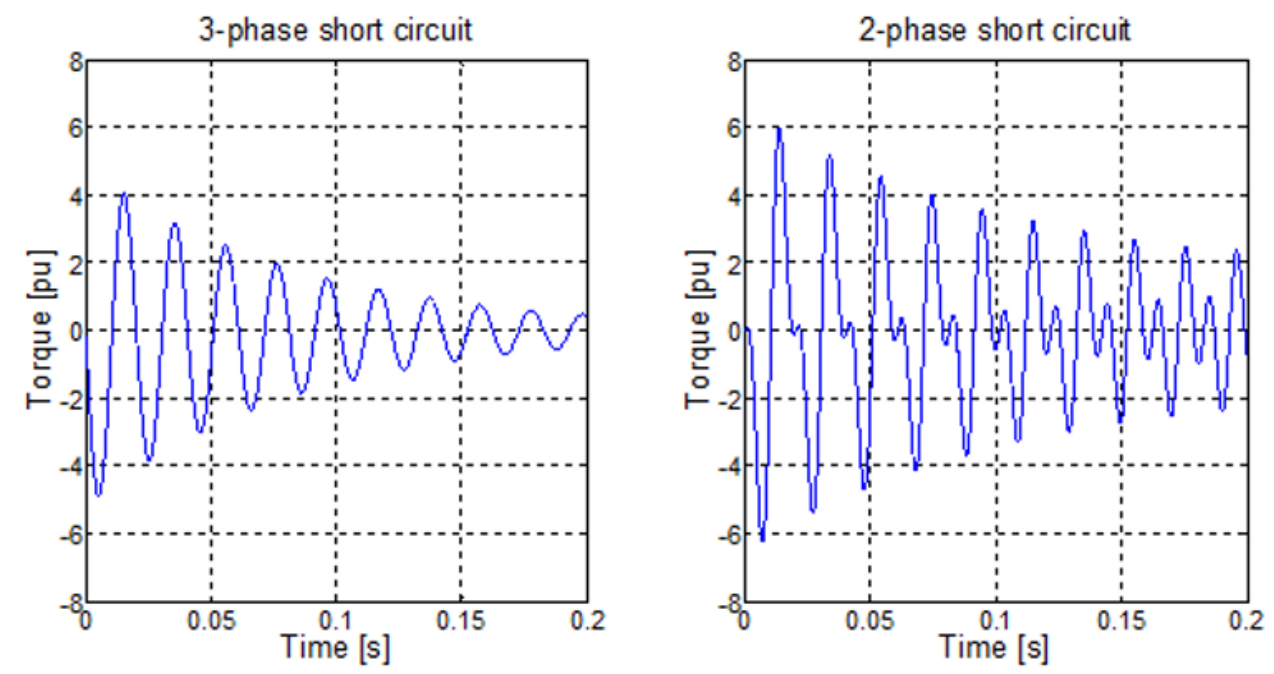

Fig. 10. Motor transient torques: 3-phase short circuit (left), 2-phase short circuit (right).

torque component matches one of the dominant torsional natural frequencies.

The torsional integrity shall be verified by a torsional analysis. Practical visualization of excitation torque components and their interaction with torsional modes over the entire speed range is by means of Campbell diagram.

Protection concept of the VFD also affects the torsional design. Many modern VFDs are fuseless. In case of major issue inside the VFD the reaction is so called protection firing which is seen by the motor as a symmetrical three-phase short circuit. Since the protection is extremely fast a phase to phase short circuit can be disregarded. The three-phase short circuit and corresponding transient torque is less harmful for the shaft system and easier to deal with as seen in Fig. 10.

Comprehensive electro-mechanical analysis of variable speed electric drive systems from torsional perspective is contained in [14]. In case the power electronic based loads are dominant loads and /or in case of island network there is certain risk of subsynchronous torsional interaction (SSTI) - see [15].

\section{Field experience}

The area of (semi) high speed electric drives is not fully new and some of the drive systems have in the meanwhile over 30 years of running experience. Tables 3 and Table 4 summarize manufacturer's experience stating the basic technical data and year of delivery. Note that tables show motor rated speed while maximum continuous speed is typically 5 to $10 \%$ higher. The reference installations incorporate motors from various manufacturers and include both new installations as well

Table 3. Field experience in high-speed electrical drives - selected LCI references.

\begin{tabular}{|c|c|c|c|c|c|}
\hline Motor technology & $\begin{array}{c}\text { Shaft power } \\
{[\mathbf{k W}]}\end{array}$ & $\begin{array}{c}\text { Rated speed } \\
\text { [rpm] }\end{array}$ & $\begin{array}{c}\text { Load } \\
\text { machine }\end{array}$ & $\begin{array}{r}\text { Year of } \\
\text { delivery }\end{array}$ & Quantity \\
\hline \multirow{21}{*}{$\begin{array}{l}\text { Synchronous, 2-pole round } \\
\text { rotor, brushless excitation, } \\
\text { sleeve bearings }\end{array}$} & 9'600 & 6’000 & Pump & 1984 & 18 \\
\hline & $8 ’ 000$ & 5'521 & Pump & 1986 & 18 \\
\hline & $13^{\prime} 000$ & 6'400 & Compressor & 1986 & 1 \\
\hline & $13^{\prime} 000$ & 5,700 & Pump & 1988 & 2 \\
\hline & $18^{\prime} 000$ & 5,500 & Compressor & 1992 & 1 \\
\hline & $41^{\prime} 000$ & 3'600 & Compressor & 1993 & 5 \\
\hline & $16^{\prime} 500$ & 4'225 & Compressor & 2002 & 1 \\
\hline & $48^{\prime} 000$ & 3'600 & Compressor & 2005 & 3 \\
\hline & $42 ’ 200$ & 3'600 & Compressor & 2005 & 1 \\
\hline & 13,500 & 6'000 & Compressor & 2008 & 1 \\
\hline & $15^{\prime} 000$ & 5'064 & Pump & 2008 & 1 \\
\hline & $14^{\prime} 500$ & 5,300 & Pump & 2009 & 1 \\
\hline & $15^{\prime} 000$ & 5'064 & Pump & 2011 & 1 \\
\hline & $48^{\prime} 000$ & 3'600 & Pump & 2014 & 1 \\
\hline & $14 ' 200$ & 4'200 & Compressor & 2015 & 1 \\
\hline & $17^{\prime} 100$ & 5,100 & Compressor & 2015 & 1 \\
\hline & $11 ' 800$ & $5 ' 050$ & Pump & 2015 & 1 \\
\hline & $8^{\prime} 470$ & 5,400 & Pump & 2015 & 12 \\
\hline & 8'000 & 5,521 & Pump & 2016 & 2 \\
\hline & $11 ' 800$ & $5 ' 050$ & Pump & 2017 & 1 \\
\hline & 8'000 & 5,521 & Pump & 2017 & 2 \\
\hline
\end{tabular}


Table 4. Field experience in high-speed electrical drives - selected VSI references.

\begin{tabular}{|c|c|c|c|c|c|}
\hline Motor technology & $\begin{array}{c}\text { Shaft power } \\
{[\mathrm{kW}]}\end{array}$ & $\begin{array}{c}\text { Rated speed } \\
{[\mathrm{rpm}]}\end{array}$ & Load machine & $\begin{array}{r}\text { Year of } \\
\text { delivery }\end{array}$ & Quantity \\
\hline Induction & $11 ' 500$ & $11 ' 200$ & Compressor & 2007 & 1 \\
\hline Induction & 6'600 & $5 ' 100$ & Compressor & 2008 & 1 \\
\hline Induction & 4'700 & $14 ’ 715$ & Compressor & 2011 & 1 \\
\hline Induction & $12^{\prime} 000$ & $10 ’ 002$ & Test stand & 2011 & 1 \\
\hline Induction & $14^{\prime} 821$ & 9'175 & Compressor & 2011 & 1 \\
\hline Induction & $14^{\prime} 060$ & 9’045 & Compressor & $2011 / 12$ & 3 \\
\hline Induction & $11 ' 460$ & 6’364 & Compressor & 2012 & 2 \\
\hline Induction & $13^{\prime} 075$ & 8'371 & Compressor & 2012 & 6 \\
\hline Induction & 7’678 & $11^{\prime} 702$ & Compressor & 2013 & 2 \\
\hline Synchronous & $10 ’ 000$ & 5'202 & Compressor & 2013 & 7 \\
\hline Induction & 4'700 & $14 ’ 715$ & Compressor & 2015 & 1 \\
\hline Induction & 5'950 & $11 ' 905$ & Compressor & 2015 & 2 \\
\hline Induction & 7'412 & $11 ' 429$ & Compressor & 2016 & 1 \\
\hline Induction & 6’635 & $10 ’ 769$ & Compressor & 2017 & 1 \\
\hline Induction & 7’000 & $10 ’ 000$ & Compressor & 2017 & 2 \\
\hline Induction & 9'500 & $12^{\prime} 000$ & Compressor & 2018 & 2 \\
\hline Induction & 11 '877 & 9'959 & Compressor & 2018 & 3 \\
\hline Induction & 8'932 & $12^{\prime} 600$ & Compressor & 2019 & 1 \\
\hline Induction & 9'068 & $12^{\prime} 600$ & Compressor & 2019 & 1 \\
\hline
\end{tabular}

as retrofit projects.

The references from Table 3 and Table 4 are graphically summarized in Fig. 11 as function of shaft power and rotor speed.

\section{Conclusion}

Use of semi high-speed and high-speed (direct) electric drives in megawatt power range as alternative to mechanical drivers and conventional geared electric drives seems to be a trend in the industry. There is already significant field experience gathered up to now: over 30 years operational experience with semi high- speed drives in speed range 3'600...6'400 rpm and over 10 years operational experience with high-speed drives with maximum speed up to $15^{\prime} 000 \mathrm{rpm}$ or even higher.

In semi high-speed range it is principally possible to use machine with 4-pole rotor and adjust the stator frequency correspondingly. Such motor design is then sub-critical (unlike 2-pole design that is normally supercritical) and allows wide controllable speed range. Utilizing wider speed range enables larger energy savings and lower operational cost / life cycle cost.

The VFD for high-speed application is a derivative of standard VFD requiring minimum adaptations. Sometimes even standard VFD can be used with no modifications required. From this perspective the VFD

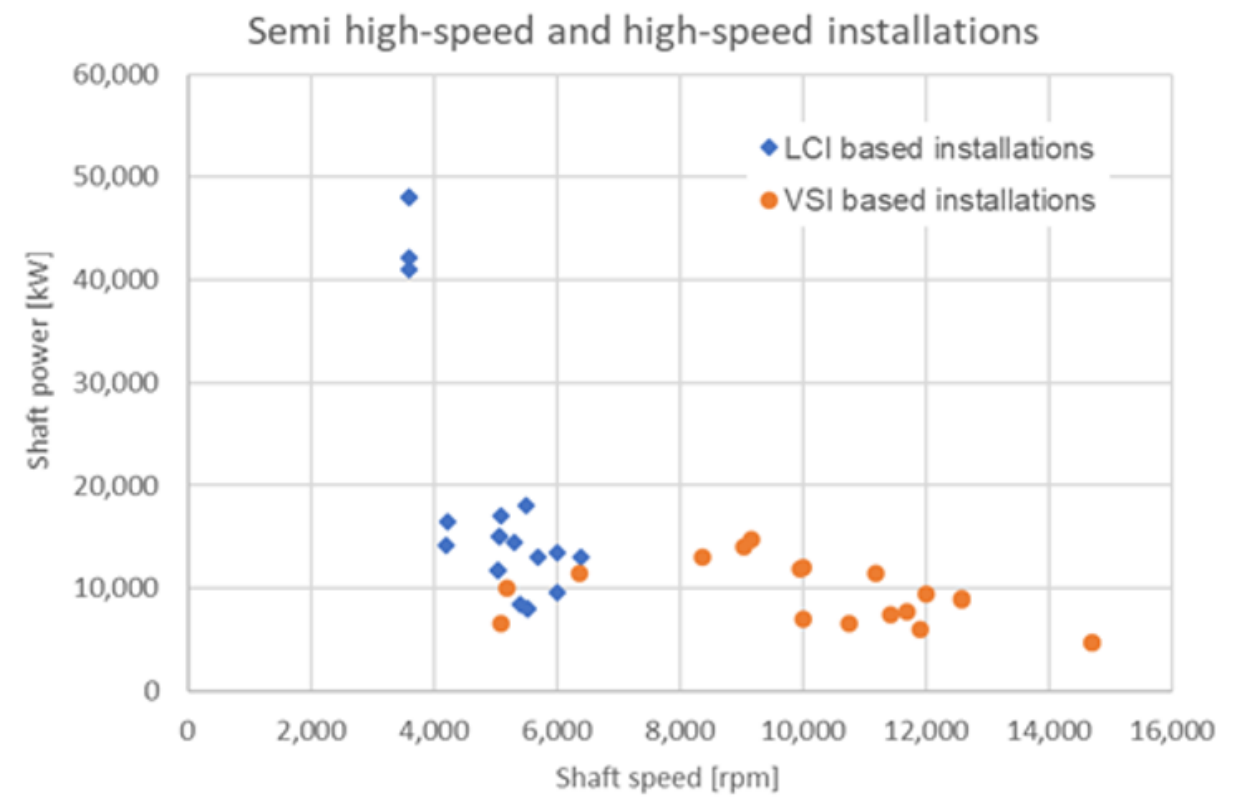

Fig. 11. (Semi) high-speed installations. 
technology fully supports the trend of going in the direction of high-speed/gearless solutions. Attention shall be paid to correct system design (e.g. protection, grounding etc).

\section{References}

[1] G.J. Neidhöfer, A.G. Troedson, Large converterfed synchronous motors for high speeds and adjustable speed operation: Design features and experience, IEEE Trans. on Energy Conversion 14, 3 (September 1999)

[2] M. Ahrens, U. Bikle, R. Gottkehaskamp, H. Prenner, Electrical Design of High-Speed Induction Motors of up to $15 \mathrm{MW}$ and 20000 rpm, IEE Conf. on Power Electronics, Machines and Drives, 487, 381-386 (2002)

[3] A. Binder, T. Schneider, High-speed inverter-fed AC drives, Int. Aegean Conference on Electrical Machines and Power Electronics, 9-16 (2007)

[4] R.R. Moghaddam, High speed operation of electrical machines, a review on technology, benefits and challenges, IEEE Energy Conversion Congress and Exposition, 5539-5546 (2014)

[5] N. Uzherov, A. Smirnov, C.H. Park, J.H. Ahn, J. Heikkinen, J. Pyrhönen, Design aspects of highspeed electrical machines with active magnetic bearings for compressor applications, IEEE Trans. on Ind. Electronics 64, 8427-8436 (2017)

[6] A. Tessarolo, G. Zocco, C. Tonello, Design and testing of a $45-\mathrm{MW} 100-\mathrm{Hz}$ quadruple-star synchronous motor for a liquefied natural gas turbo-compressor drive, IEEE Trans. on Industry Applications 47, 3, 1210 - 1219 (May/June 2011)

[7] T. Holopainen, P. Jörg, O. Liukonnen, Comparison of two- and four-pole VSD motors up to 4000 RPM, $45^{\text {th }}$ Turbomachinery and $32^{\text {nd }}$ Pump Symposia, Houston, Texas (2016)

[8] T. Mauffrey, J-F. Pradurat, L. Durantay, J. Fontini, Comparison of 5 different squirrel cage rotor designs for large high speed induction motors, PCIC Europe 2013, Istanbul, Turkey (2013)

[9] J.K. Steinke, R. Vuolle, H. Prenner, J. Järvinen, New variable speed drive with proven motor friendly performance for medium voltage motors, IEEE International Electric Machines and Drives Conference IEMDC'99, 235-239 (1999)

[10] IEC 60034-18-42: Rotating electrical machines Part 18-42: Partial discharge resistant electrical insulation systems (Type II) used in rotating electrical machines fed from voltage converters Qualification tests (2017)

[11] T. Holopainen, P. Jörg, J. Niiranen, D. Andreo, Electric motors and drives in torsional vibration analysis and design, $40^{\text {th }}$ Turbomachinery Symposium, Houston, Texas (2013)
[12] M. Bruha, Z. Peroutka, Torsional vibration in large variable speed drive systems: Origin and mitigation methods, EPE'15 ECCE-Europe $-17^{\text {th }}$ European Conference on Power Electronics and Applications, Geneve, Switzerland (2015)

[13] M. Bruha, et al., Torsional issues related to variable frequency control of elastic drive systems, IECON $2016-37^{\text {th }}$ Annual Conference on IEEE Industrial Electronics Society, Florence, Italy, 2981-2987 (2016)

[14] M. Bruha, Electro-mechanical interaction between electric drive and its mechanical load and control interventions mitigating unwanted vibration phenomena: PhD thesis (University of West Bohemia, 2018)

[15] P. Jörg, A. Tresch, M. Bruha, A model based approach to optimize controls of a large LCI VSD for minimal grid-side sub-synchronous torsional interaction, PCIC Europe 2013, Istanbul, Turkey, (2013) 